\title{
VULNERABILITY ASSESSMENT OF MODULAR STEEL PLATFORM STRUCTURES UNDER SEISMIC LOADS
}

\author{
YASSER S. SALEM ${ }^{1}$, ZHANG JIN², YANYAN HUANG ${ }^{2} \&$ TIFFANY YOO ${ }^{3}$ \\ ${ }^{1}$ California State Polytechnic University Pomona, USA \\ ${ }^{2}$ Hubei University, China \\ ${ }^{3}$ FWC Structural Engineers, USA
}

\begin{abstract}
Modular steel structures are the standard method of construction in the arctic region. In this study, the feasibility of retrofitting these structures, using friction dampers, is evaluated. These structures possess some unique detailing that is the result of the method of construction used for them. This detailing is believed to contribute to the vulnerability of these structures during major seismic events. Analytical fragility curves are developed to evaluate the benefit of using friction dampers in reducing the risk of damages during significant earthquakes. The methodology that was used to develop the curves is based on calculating the maximum story drift using nonlinear time history analysis for different ground motions with different intensities and frequencies. The produced fragility curves highlight the advantages of using friction dampers in reducing the level of damage these structures can experience during earthquakes.

Keywords: modular steel structures, analytical fragility curves, friction dampers.
\end{abstract}

\section{INTRODUCTION}

Modular steel structures are getting more popular in the oil and gas industry in which cast-in-place methods are replaced by standard construction methods. Using modular structures, construction project teams not only can reduce the number of workers on sites, but also can speed up their construction process, control project quality and avoid the influence of weather and other unknown factors.

These modular structures are often pre-assembled offshore and are transported to their final location. They are mounted on top of support steel piles, with a connection that would allow for thermal expansion as well as clearance for lateral adjustment at their final location. The superstructure is constructed from structural steel where gravity loads are carried by steel columns and beams and the floor assembly is made from built-up plate girders. The lateral resisting system is concentric steel brace elements. The plate girders span over the width of the module and are supported on steel piles. The piles usually project from the finish grade a distance that ranges from ten to fifteen feet to the bottom of the plate girders. This is to allow for the free movement of the wildlife below the platform level. Fig. 1 shows an example of a typical modular steel structure that is considered in this study.

Piles are usually made from tubular steel. The piles are usually installed in a drilled shaft in the permafrost soils. The sources of strength for the pile are driven from the tangential adfreeze bond strength between the slurry and the steel pile after the slurry reaches subfreezing temperature.

The adfreeze strength provide a resistance to the pile's lateral movement, this resistance increases as the piles are embedded deeper into the permafrost. The piles are considered to behave as cantilever columns with a point of fixity at the location of the pile longitudinal axes that has zero lateral deformation. The extreme cold together with the cantilever action of the piles impact the ductility of these structures especially for old structures built prior to seismic provisions were implemented by modern building codes. 


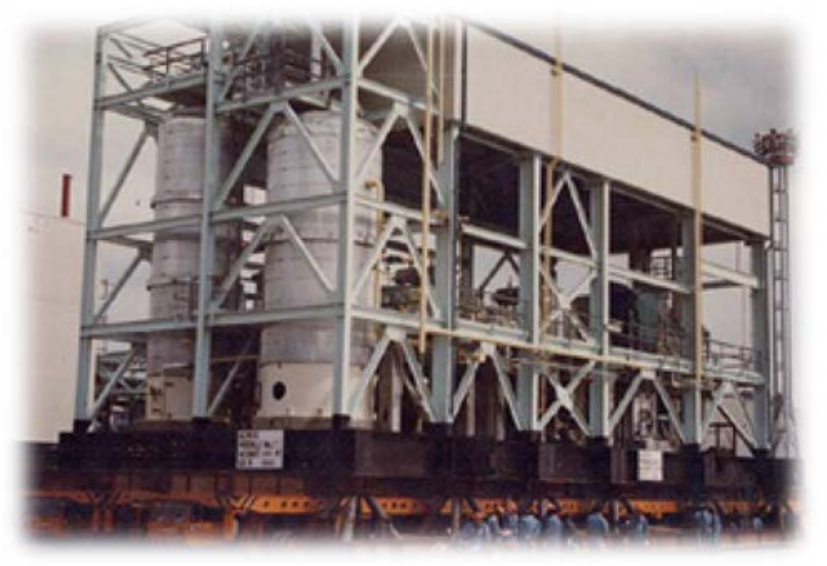

Figure 1: Example of a modular steel structure during land transportation to final site location.

Friction dampers is an attractive retrofit solution to these types of structures when it is compared to other damper types such as viscous and visco-elastic dampers as they are less sensitive to the extreme temperature in the arctic region. Friction devices primarily use automotive brakes as an analogy [1] to their function on dissipating energy. Friction devices generate energy rectangular hysteric loops similar to the characteristic of coulomb friction. Fig. 2 illustrates a schematic diagram of pall friction device and Fig. 3 shows the typical force displacement relationship for friction dampers.

Fig. 4 shows the acceleration response spectra of the N-S components of 1985 Mexico City Earthquake under various damping ratios. The reduction of the spectral acceleration with the increase of damping is readily seen in this graph. One important observation from this graph is the acceleration reduction with the increase of damping is effective only in the

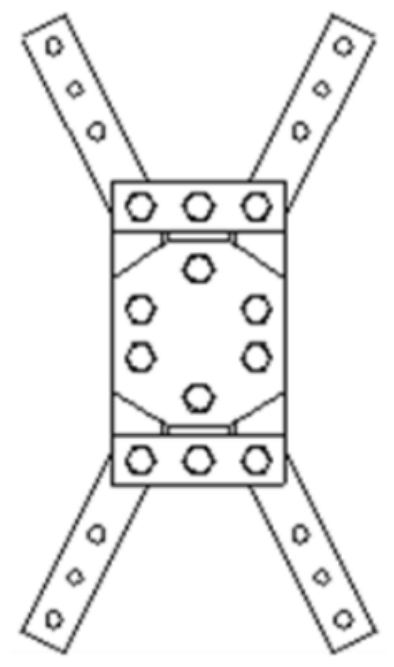

Figure 2: Pall friction device [1]. 


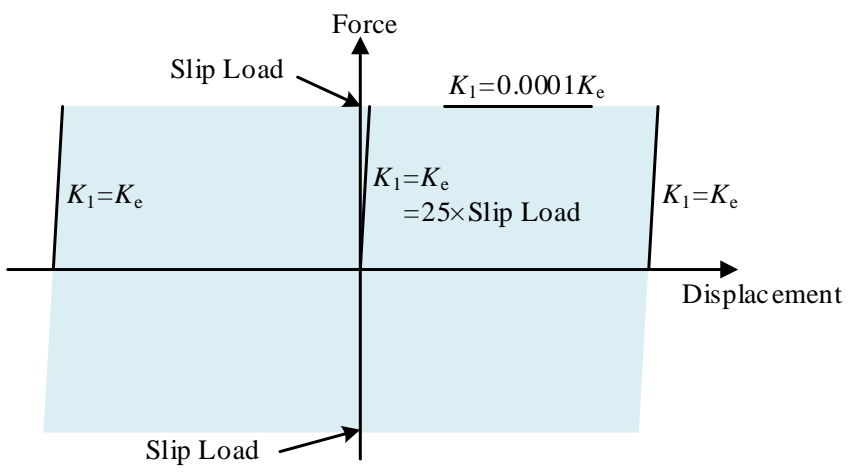

Figure 3: Theoretical hysteresis loops for a typical friction damper [2].

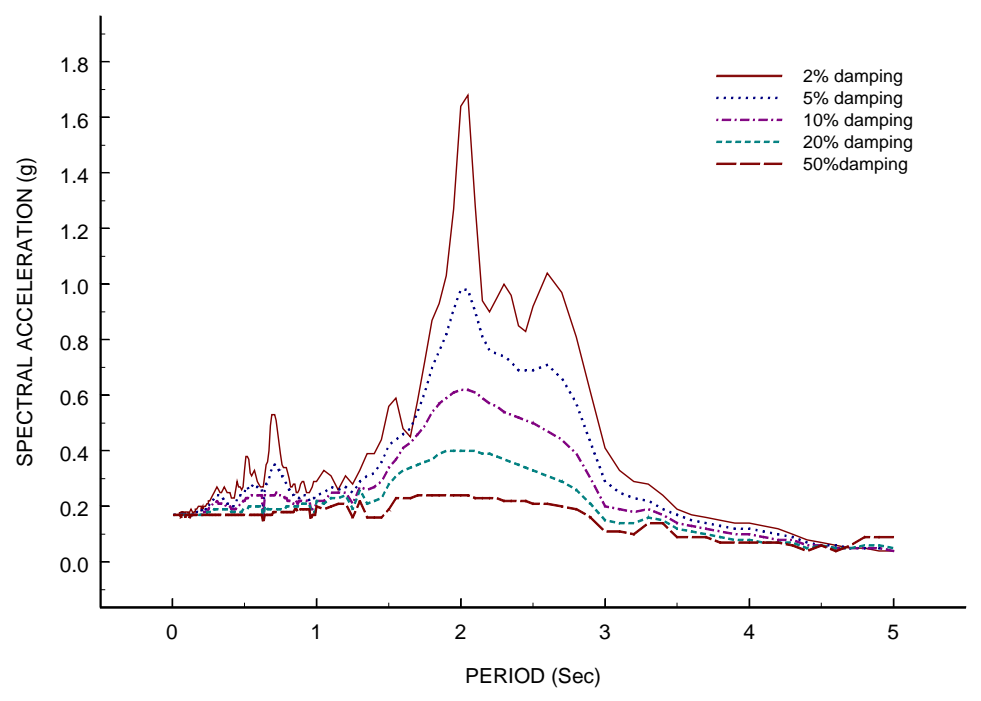

Figure 4: Response spectra acceleration (SA) Mexico earthquake, September 1985 [3].

range of 1.5 to 3.0 seconds of the natural period. This indicates that increasing the system damping has the potential to reduce the seismic demands to these structures. The supplemental damping devices can also reduce the story drift which is an important metric in determining the risk of damage to framed structures during earthquakes [3]. In this study, analytical fragility curves were used to assess the effectiveness of friction dampers to retrofit these structures.

\section{METHODOLGY}

A typical archetype modal structure is considered within the scope of this study. The same building is retrofitted by adding a brace-damper system within the structure in the space between the bottom of the cantilever steel pile and the bottom of the steel platform. 3D and elevation views of both buildings are shown in Figs 5 and 6. 


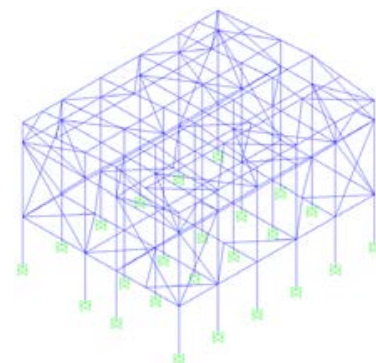

(a)

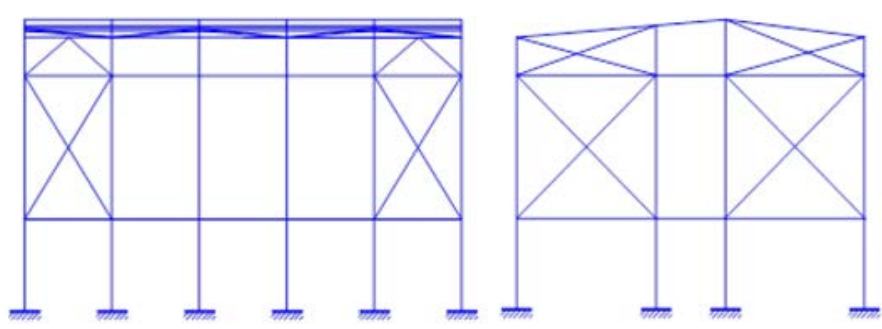

(b)

(c)

Figure 5: Archetype modular structure. (a) 3-D view; (b) View in long direction; and (c) View in trans. direction.

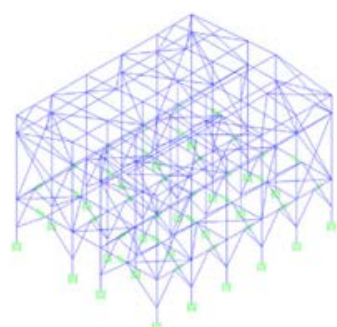

(a)

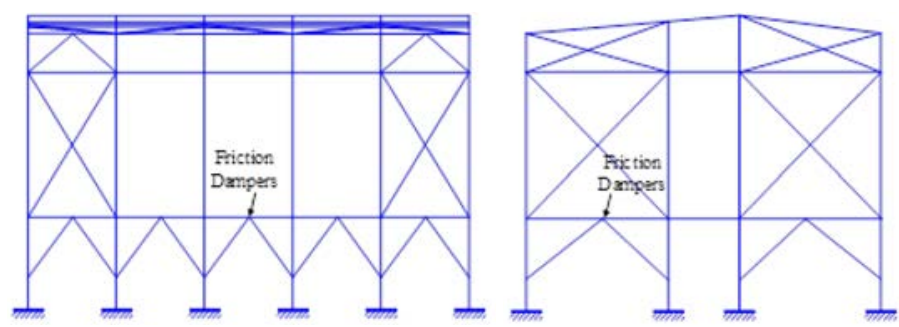

(b)

(c)

Figure 6: Archetype modular structure retrofitted with friction dampers. (a) 3-D view; (b) View in long direction; and (c) View in trans. direction.

The archetype structure was modelled based on the nonlinear behaviour of materials and its damping characteristics. An Eigen value modal analysis were conducted to determine the structure dynamic properties. Table 1 shows the natural period of the first 10 modes before and after the retrofit for the archetype structure. Pushover curves and inter-story drift ratio of the archetype structure at each step of pushover analysis were determined using SAP2000@ software package [4]. A time history analysis was carried out to determine the response of structure based on 22 far field ground motions [5], as well as near field ground motions, selected from (PEER) ground motion database. Fig. 7 shows the response spectra for the 22 ground motions that were used in this study. From the graph, the selected ground motions represent a wide verities of earthquake records that have different peak ground accelerations (PGA) and frequency contents.

\subsection{Analytical model of sample structure}

To perform the pushover analysis, the nonlinear time history dynamic analysis, and to evaluate the vulnerability of the considered buildings, the building frames have been modelled using SAP 2000@ software. The nonlinear or inelastic behaviour of various structural members, such as beams, columns, and bracing elements, plastic hinge has been introduced to the software based on the FEMA 356 guidelines [7]. For beams and columns, the general behaviour is shown in Fig. 8, and for bracing elements that carry the friction 
Table 1: Structure dynamic properties.

\begin{tabular}{|c|c|c|c|c|c|}
\hline \multirow{2}{*}{ Mode No. } & \multicolumn{5}{|c|}{ Period (sec) } \\
\cline { 2 - 6 } & No Retrofit & $\begin{array}{c}5 \% \\
\text { Damping }\end{array}$ & $\begin{array}{c}10 \% \\
\text { Damping }\end{array}$ & $\begin{array}{c}15 \% \\
\text { Damping }\end{array}$ & $\begin{array}{c}20 \% \\
\text { Damping }\end{array}$ \\
\hline 1 & 0.9438 & 0.5883 & 0.5802 & 0.5778 & 0.5773 \\
\hline 2 & 0.8846 & 0.4668 & 0.4186 & 0.4109 & 0.4079 \\
\hline 3 & 0.8472 & 0.4326 & 0.3846 & 0.3811 & 0.3809 \\
\hline 4 & 0.8471 & 0.4041 & 0.3809 & 0.3806 & 0.3805 \\
\hline 5 & 0.7514 & 0.3861 & 0.3802 & 0.3802 & 0.3802 \\
\hline 6 & 0.6789 & 0.3802 & 0.3802 & 0.3802 & 0.3802 \\
\hline 7 & 0.6426 & 0.3802 & 0.3802 & 0.3802 & 0.3802 \\
\hline 8 & 0.6163 & 0.3802 & 0.3802 & 0.3802 & 0.3802 \\
\hline 9 & 0.6011 & 0.3802 & 0.3801 & 0.3801 & 0.3801 \\
\hline 10 & 0.5070 & 0.3802 & 0.3801 & 0.3801 & 0.3801 \\
\hline
\end{tabular}

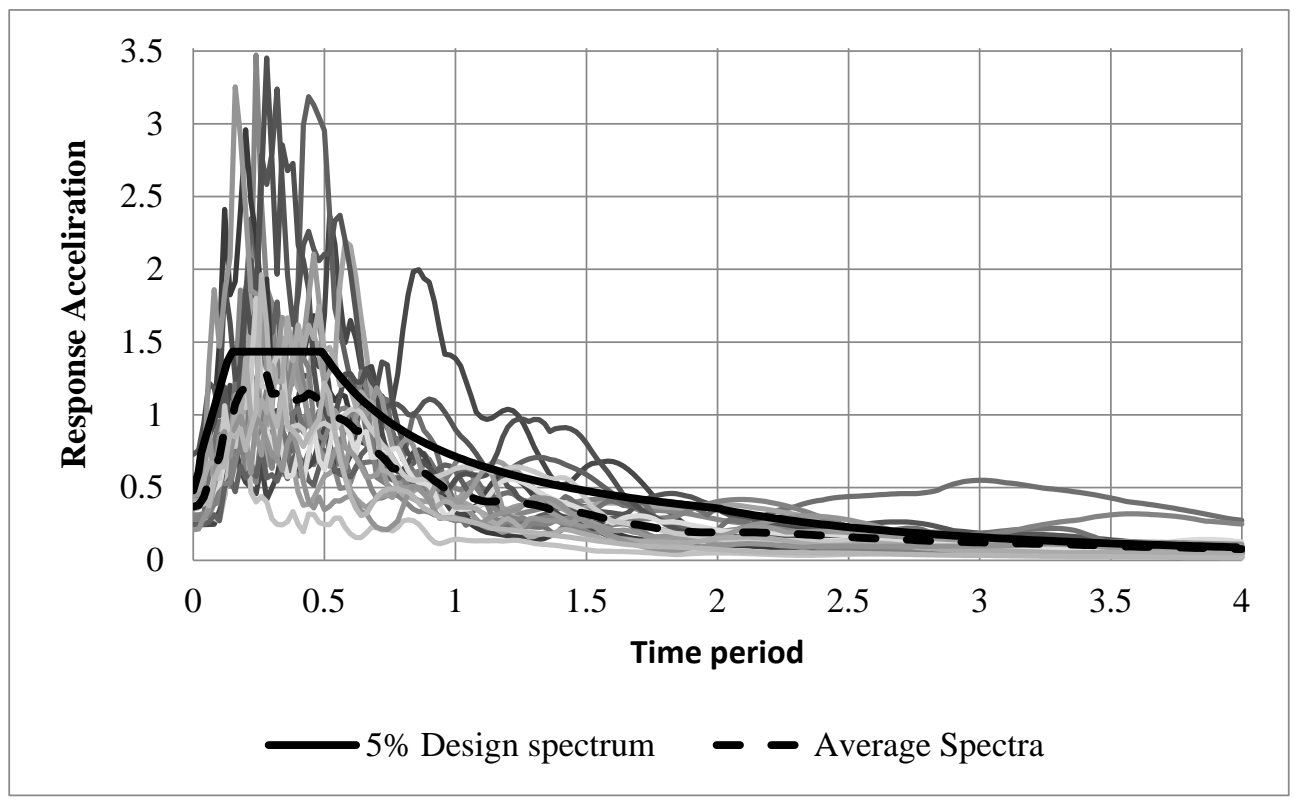

Figure 7: Response spectra acceleration (SA) for the 22 ground motion records used in the dynamic analysis.

dampers, the model that is shown in Fig. 9 was used. The hysteric force displacement relationship for a typical WT brace member which is the cross section commonly used in these structures is shown in Fig. 10. It can be seen from Fig. 11 that the effect of brace buckling on the overall ductility performance of the system is considerably low compared to that of other ductile systems. The parameters used in Fig. 9, which defines the inelastic behaviour of bracing elements, are calculated by the following formulas. The parameters for this plastic hinge model can be determined by using eqn (1): 


$$
P_{c}=1.7 F_{a} \mathrm{~A},
$$

where $F_{a}$ is the allowable axial stress obtained from AISC Table 4, A is the area of the brace cross section, and Pc represents the compressive axial force of the brace member. With $\mathrm{P}_{c}$, deformation of the brace member can be calculated by using eqn (2):

$$
\Delta_{c}=\frac{P_{c} L}{E A},
$$

where $\mathrm{L}$ is the length of the brace member.

For the tension side of the force-deformation relation model, the axial force and the deformation is defined as $P_{y}$ and $\Delta_{y}$ are the brace axial force and displacement, respectively, where the $F_{y}$ is the yield stress of the steel.

$$
\begin{gathered}
P_{y}=F_{y} \mathrm{~A}, \\
\Delta_{y}=\frac{P_{y} L}{E A} .
\end{gathered}
$$

Fig. 5 depicts the plastic hinge model of the brace frame used in the structure which is WT12X52 section.

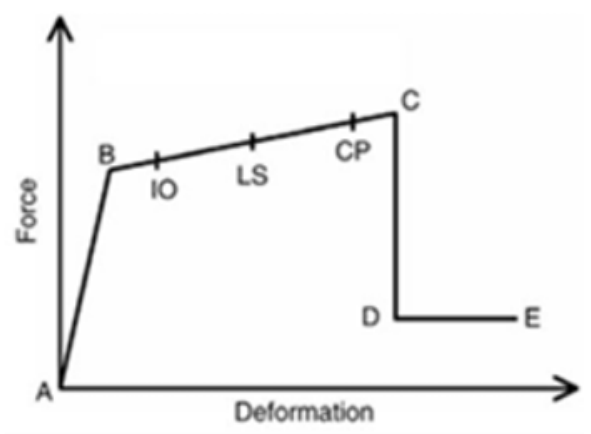

Figure 8: Inelastic model used for beams and columns [5].

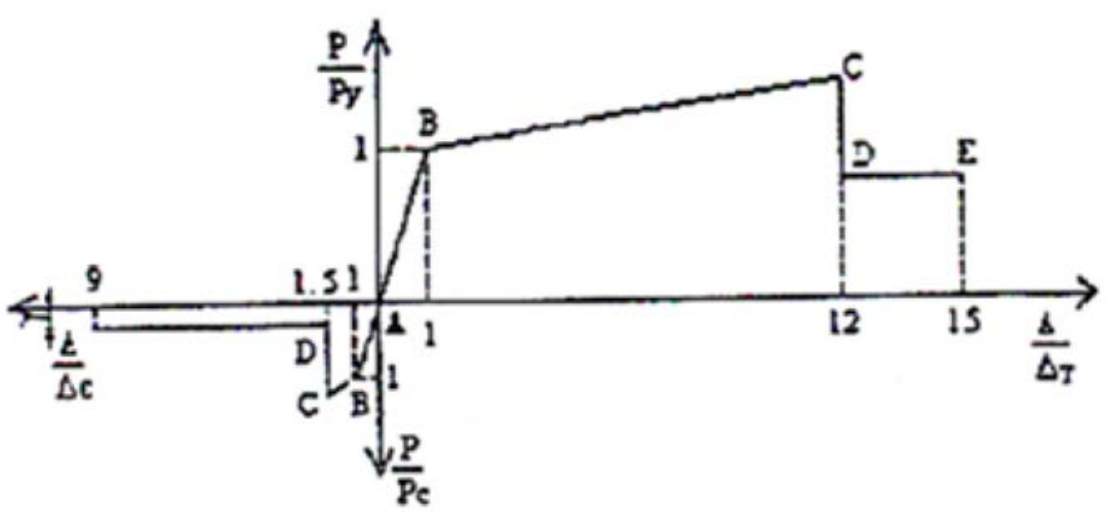

Figure 9: Inelastic model used for bracing elements [7]. 


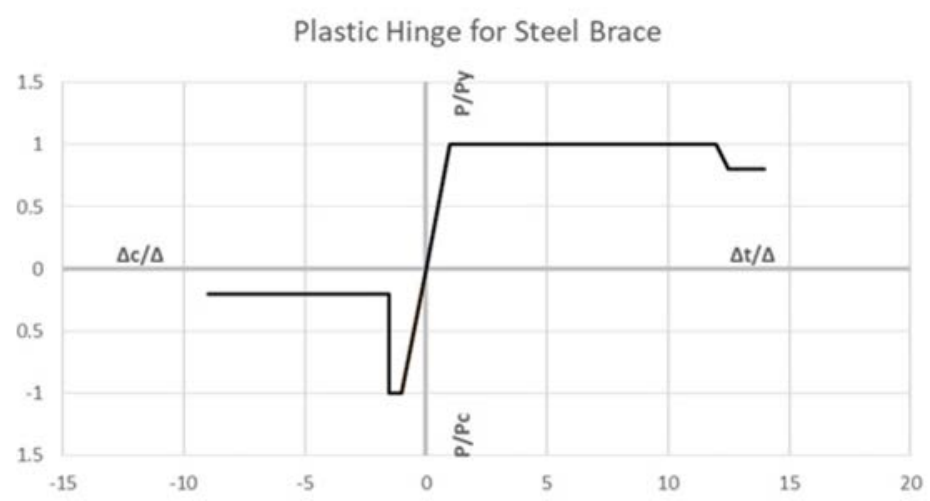

Figure 10: Plastic hinge properties for a typical brace member.

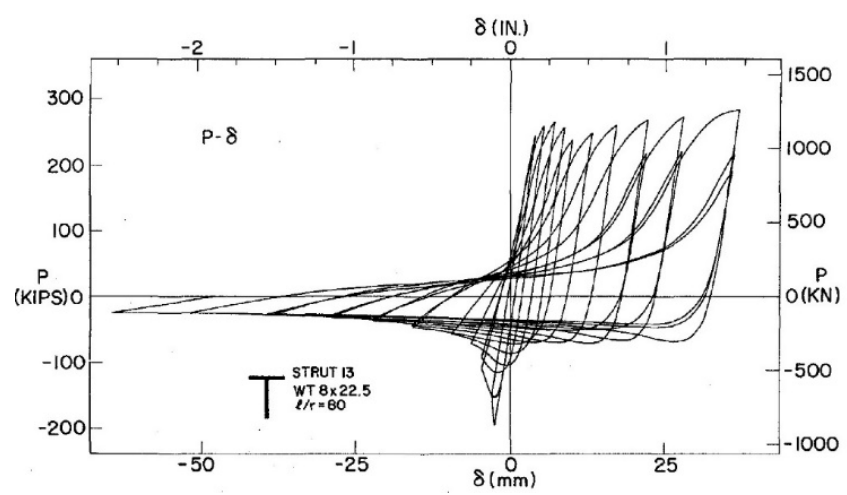

Figure 11: Force displacement relationship for a WT brace member under cyclic loading [6].

\subsubsection{Friction dampers}

To account for the additional system damping produced from supplemental damping devices, FEMA 356 specifies a damping modification factor to reduce the seismic effect (pseudo lateral load in a given horizontal direction) on the structure. The damping modification factor comes from the estimated effective damping ratio $\beta_{\text {eff }}$, which is expressed as follows for a structure with linear viscous dampers [7].

$$
\begin{gathered}
\beta_{\text {eff }}=\beta+\frac{\sum_{j} W_{j}}{4 \pi W_{k}}, \\
W_{k}=\frac{1}{2} \sum_{i} F_{i} \delta_{i},
\end{gathered}
$$

where $\beta$ is the damping ratio of the structure without any devices, $W_{j}$ is the work done by device $\mathrm{j}$ in a complete cycle corresponding to floor displacement $\delta_{i}$. $W_{k}$ is the maximum strain energy in the frame and $F_{i}$ is the inertia force in floor i [7].

The force-displacement relationship of the nonlinear damper is expressed as follows:

$$
F=K_{e f f} D
$$


where $\mathrm{F}$ is the damper force, $\mathrm{D}$ is the displacements across the damper, and $K_{\text {ef } f}$ is the stiffness of the brace and the damping device which can be calculated from the force displacement diagrams of the device.

Using eqns (5) and (6), the approximate damping ratios of the system can be estimated, and the supplemental damping devices can be sized to achieve the desired damping ratios. In this study damping ratios of $5 \%, 10 \%, 15 \%$ and $20 \%$ of the entire system were considered. Table 2 shows the structure properties of the dampers that are used in this study at different damping ratios.

Table 2: Friction damper properties.

\begin{tabular}{|c|c|c|c|c|c|c|}
\hline & \multicolumn{3}{|c|}{$\begin{array}{c}\text { Dampers properties in X } \\
\text { direction }\end{array}$} & \multicolumn{3}{c|}{ Dampers properties in the Y } \\
direction
\end{tabular}

Fig. 12 shows the force displacement relationships for the dampers that were used in this research at different damping ratios. It can be seen that as the damping ratio increased the energy absorbed by the dampers increased. Fig. 13 shows the push over curves for the structure in both the transverse and longitudinal directions. The buckling load in the braces in relationship to the other limit states (failure criteria) that were used in this study are shown in this figure where it can be seen that the buckling of the braces is the most critical limit state compared to pile failure or the story drift.

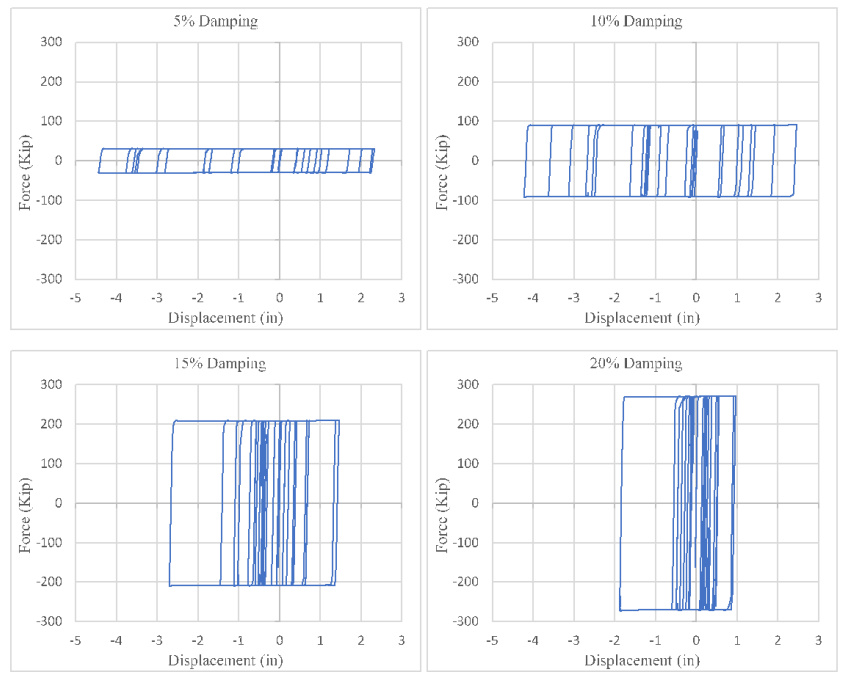

Figure 12: Damper force displacement relationship for different damping ratios. 

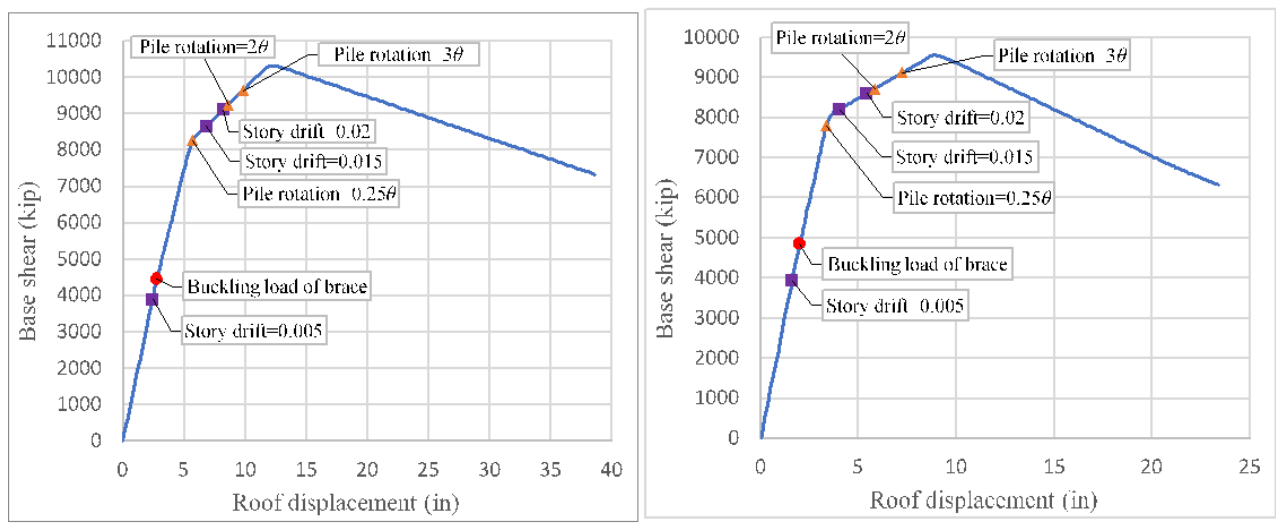

Ground Motion in UX direction

Ground Motion in UY direction

Figure 13: Push over curves for the modular structure.

\subsubsection{Analytical fragility curves}

Fragility curves express the probability of reaching or exceeding the specific limit state at a given level of ground shaking intensity. Log-normal distribution for damage probability is a common assumption in the literature [8].

A log-normal distribution is used because all values are expected to be positive. The probability of reaching or exceeding a Limit State (LS) at a given earthquake intensity is given by eqn (8):

$$
P\left[D S_{i} \mid S_{a}\right]=\varphi\left[\frac{1}{\beta_{d s}} \ln \left(\frac{S_{a}}{S_{a, d s}}\right)\right],
$$

where $\varphi$ is the standard log-normal cumulative distribution function; $S_{a}$ is the spectral acceleration amplitude (PGA in this case); $S_{a, d s}$ is the median value of spectral acceleration (PGA) at which the building reaches the threshold of damage state, $d s$; and $\beta_{S d s}$ is the normalized composite log-normal standard deviation respectively. Demand spectra and capacity curves are described probabilistically by median properties and variability parameters, $\beta_{D}$ and $\beta_{C}$, respectively [8].

$$
S_{a, d s}=\delta_{R, S_{d s}} \alpha_{2} h \delta_{R, S_{d s}}
$$

To account for variability, FEMA uses eqn (10):

$$
\beta_{S_{d s}}=\sqrt{\left(\operatorname{CONV}\left[\beta_{C}, \beta_{D}, S_{d, S_{d s}}\right]\right)^{2}+\left(\beta_{M\left(S_{d s}\right)}\right)^{2}},
$$

where $\beta_{S d s}$ is the log-normal standard deviation that describes the total variability for structural damage state, $d s ; \beta_{C}$ is the log-normal standard deviation parameter that describes the variability of the capacity spectrum; $\beta_{D}$ is the log-normal standard deviation parameter that describes the variability of the demand spectrum; $\beta_{M(S d s)}$ is the log-normal standard deviation parameter that describes the uncertainty in the estimation of the median value of the threshold of structural damage state, ds [8].

The variability of building response depends jointly on demand and capacity since capacity curves are nonlinear. The function "CONV" implies a complex process of 
convolving probability distributions of the demand spectrum and the capacity curve, respectively.

\section{RESULTS AND ANALYSIS}

To assess the effectiveness of the retrofit using friction dampers, three criteria were used in this study. Criterion 1 is the axial deformation of the braced frames which represent the buckling failure of the WT shapes. Criterion 2 is the story drift between the base and the plate girder platform. Criterion 3 is the bending of the steel piles.

The fragility curves were developed for the three main performance levels prescribed in FEMA 356 which are immediate occupancy (IO), life safety (LS) and collapse prevention (CP). The 0.5 PGA was used as a point of reference to compare structure performances for all three criteria for the different performance levels. The 0.5 PGA represents the design basic earthquake (DBE) which represent an earthquake that has a $10 \%$ probability of exceedance in 50 years. For the axial deformation of the vertical braces (criterion 1), Figs 14-18 show that increasing the system damping reduced probability of failure from $57 \%$ to $30 \%$ for the life safety performance level while the collapse prevention was reduced from $40 \%$ to $9 \%$. On the other hand, increasing the damping ratio does not have any effect on reducing the probability of failure in the Immediate Occupancy performance level. Tables 3-5 summarize the structure performance as it relates to criterion 1. For the story drift criterion, increasing damping ratio from $2 \%$ to $20 \%$ reduced the probability of failure from $100 \%$ to $63 \%$ for the immediate occupancy level, $67 \%$ to $1 \%$ for the life safety performance level and $24 \%$ to $0 \%$ for the collapse prevention performance level. For the pile bending (criterion 3), increasing the damping ratio reduce the probability of failure from $68 \%$ to $3 \%$ for the $2 \%$ damping to $20 \%$ damping ratio, while it reduced from $12 \%$ to $1 \%$ for the life safety performance level and from $7 \%$ to $0 \%$ for the collapse prevention performance level. It should be noted that the structure performance at $20 \%$ damping is even worse than the result at $15 \%$ damping. This can be explained due to the fact that the damper slip load of 15\% is $208 \mathrm{kip}$ (925 kN) while for $20 \%$ is 270 kip $(1,201 \mathrm{kN})$.

The results indicated that increasing the slip load in the damper is not an effective solution especially for criterion 2, because larger force is needed to initiate the damping mechanism of the friction damper, leading to larger deformation of the braces members. Therefore, the $15 \%$ damping ratio is the optimal value for the retrofit of this system.

\section{CONCLUSIONS}

Fragility analysis has been widely used in performance-based design (PBD) over the last decades to assess the response of different structure systems. In the context of PBD, fragility assessment modular steel structures subjected to earthquake hazards is conducted in this study. This study revealed that the friction dampers were effective in reducing the risk of damages for modular steel structures.

The fragility curve analysis shows clear improvements in increasing the damping ratios. It is noticed that there is no significant improvement when the damping ratio of the system was increased from $10 \%$ to $20 \%$. It also found that the $15 \%$ damping ratio is the optimum value for improved performance for all criteria considered in this study. 

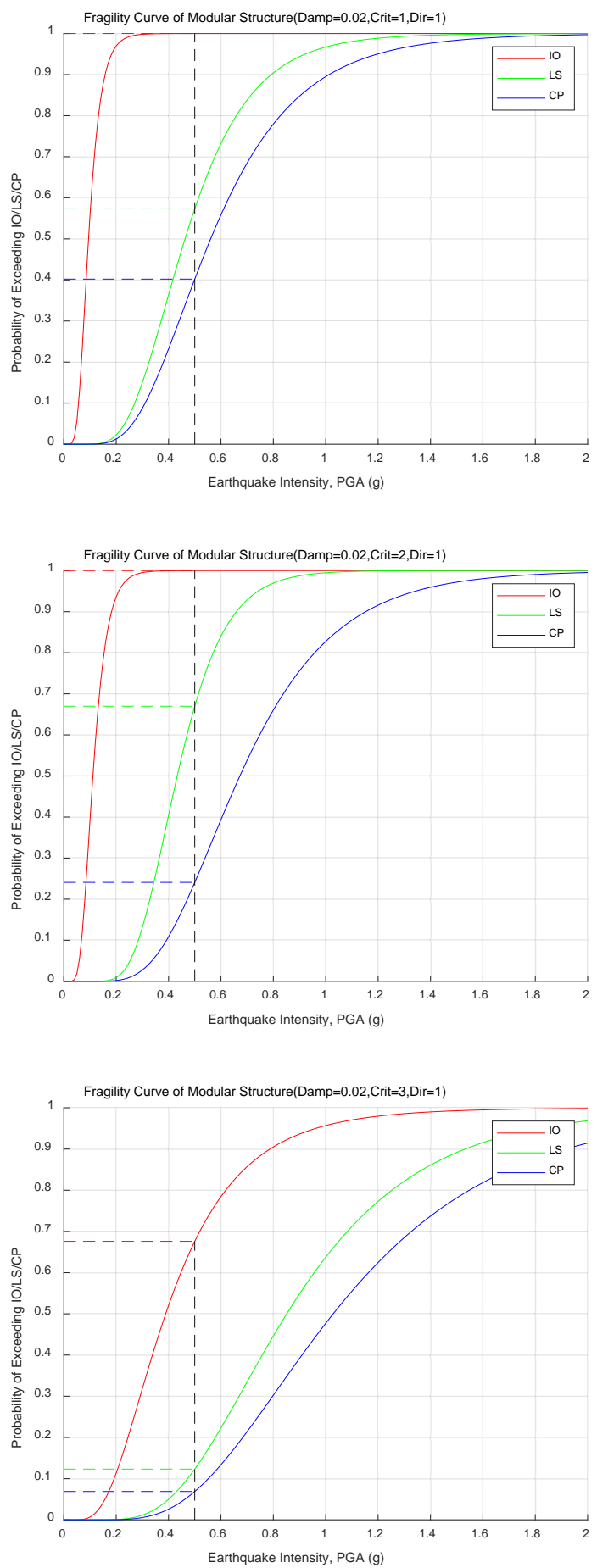

Figure 14: Fragility curves for existing structure (2\% modal damping). 
PII-56 Earthquake Resistant Engineering Structures XII
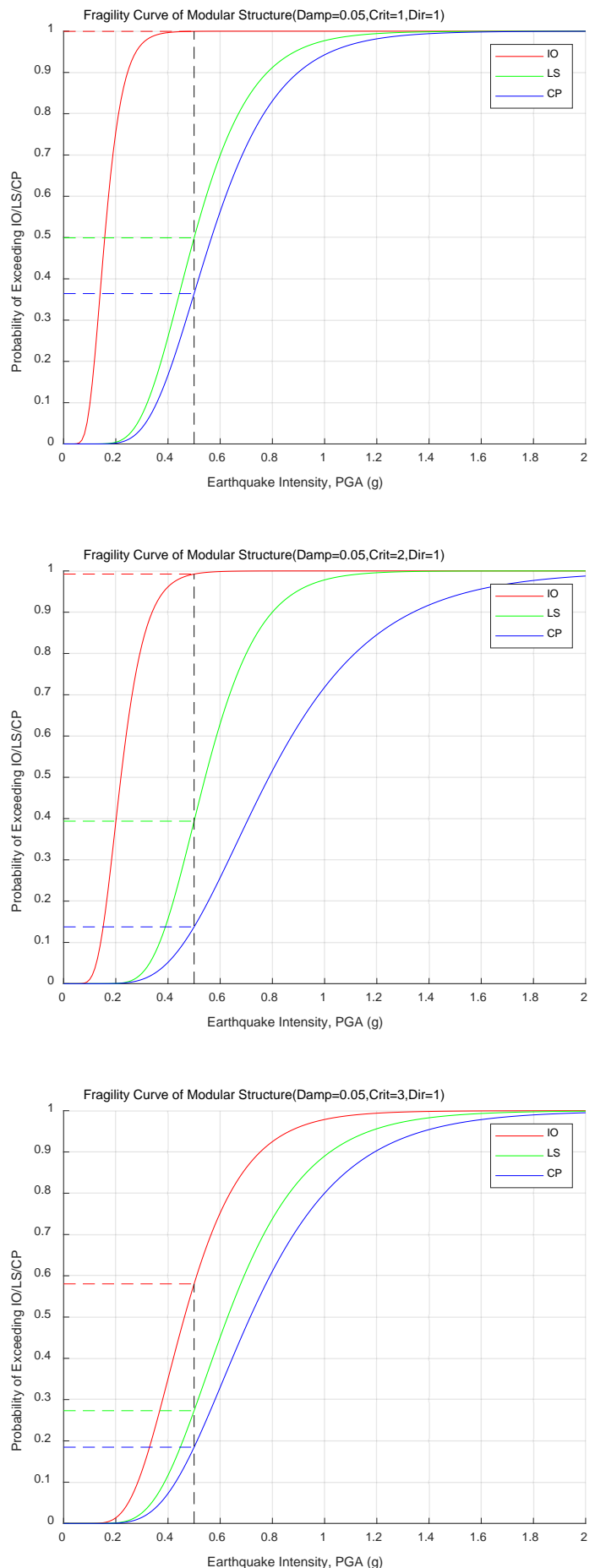

Figure 15: Fragility curves for retrofitted structure (5\% damping). 

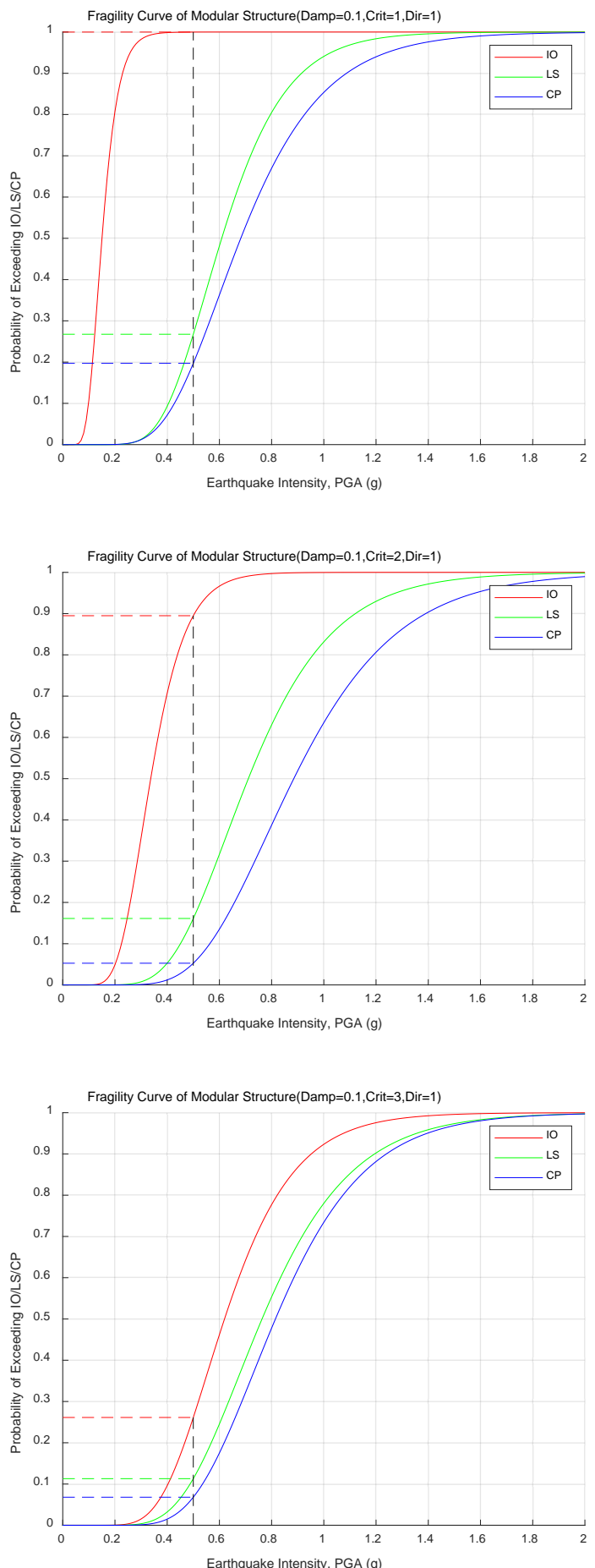

Figure 16: Fragility curves for retrofitted structure (10\% damping). 
PII-58 Earthquake Resistant Engineering Structures XII
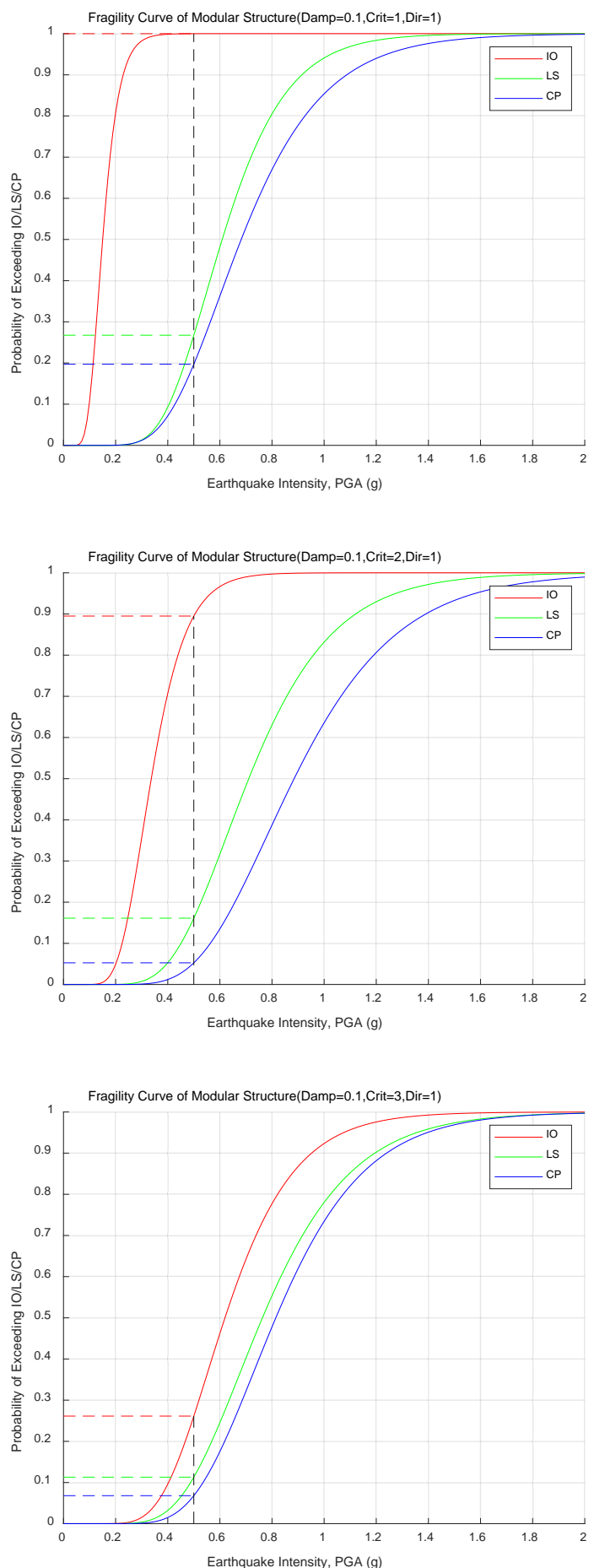

Figure 17: Fragility curves for retrofitted structure (15\% damping). 

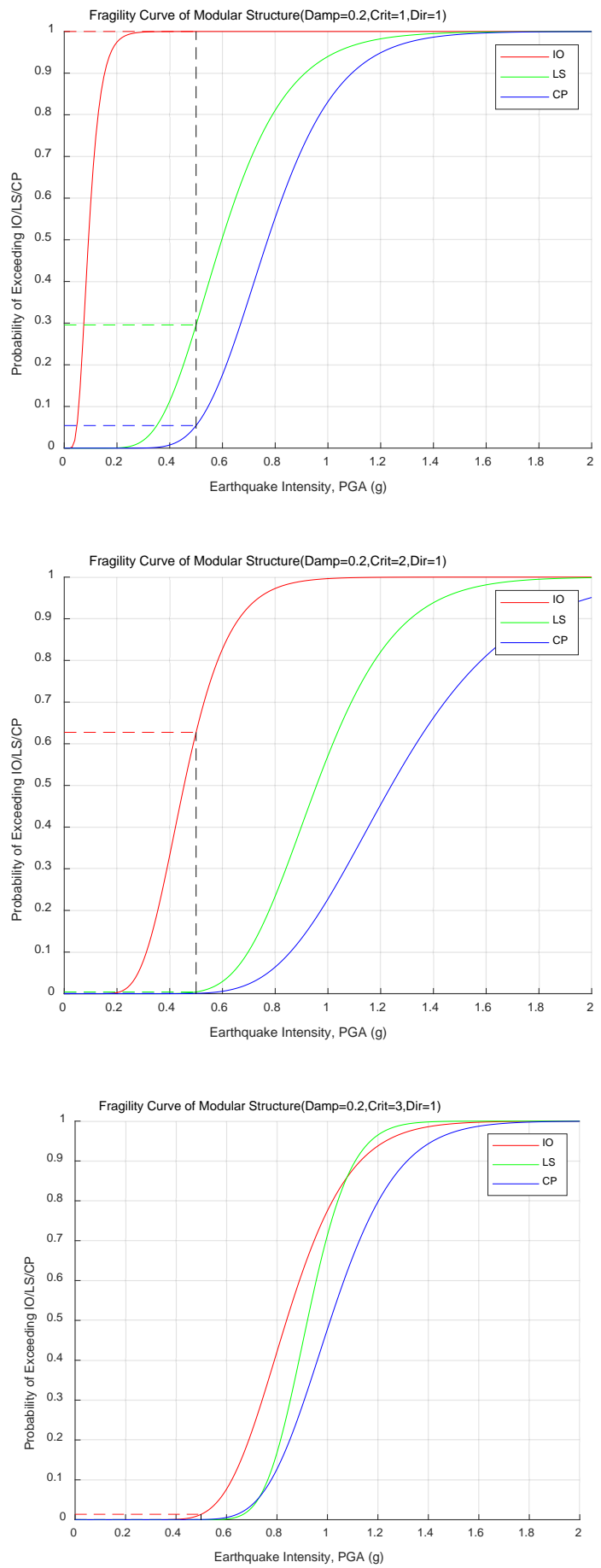

Figure 18: Fragility curves for retrofitted structure (20\% damping). 
Table 3: Probability of failure at different performance levels for criterion 1 (brace axial deformation).

\begin{tabular}{|c|c|c|c|}
\hline \multirow{2}{*}{ Damping ratio } & \multicolumn{3}{|c|}{ Performance level } \\
\cline { 2 - 4 } & IO & LS & CP \\
\hline $2 \%$ & 100 & 57 & 40 \\
\hline $5 \%$ & 100 & 50 & 36 \\
\hline $10 \%$ & 100 & 26 & 21 \\
\hline $15 \%$ & 100 & 13 & 6 \\
\hline $20 \%$ & 100 & 30 & 9 \\
\hline
\end{tabular}

Table 4: Probability of failure at different performance levels for criterion 2 (story drift).

\begin{tabular}{|c|c|c|c|}
\hline \multirow{2}{*}{ Damping ratio } & \multicolumn{3}{|c|}{ Performance level } \\
\cline { 2 - 4 } & IO & LS & CP \\
\hline $2 \%$ & 100 & 67 & 24 \\
\hline $5 \%$ & 99 & 39 & 11 \\
\hline $10 \%$ & 89 & 16 & 6 \\
\hline $15 \%$ & 66 & 2 & 1 \\
\hline $20 \%$ & 63 & 1 & 0 \\
\hline
\end{tabular}

Table 5: Probability of failure at different performance levels for criterion 3 (pile bending).

\begin{tabular}{|c|c|c|c|}
\hline \multirow{2}{*}{ Damping ratio } & \multicolumn{3}{|c|}{ Performance level } \\
\cline { 2 - 4 } & IO & LS & CP \\
\hline $2 \%$ & 68 & 12 & 7 \\
\hline $5 \%$ & 57 & 27 & 16 \\
\hline $10 \%$ & 25 & 11 & 8 \\
\hline $15 \%$ & 4 & 1 & 8 \\
\hline $20 \%$ & 3 & 1 & 0 \\
\hline
\end{tabular}

\section{REFERENCES}

[1] Pall, A. \& Marsh, C., Response of friction damped braced frame. Journal of Structural Engineering, 108(6), 1982.

[2] Quaketek, www.quaketek.com/.

[3] Hanson, R.D. \& Soong, T.T., Seismic Design with Supplemental Energy Dissipation Devices, Earthquake Engineering Research Institute: Pasadena, p. 135, 2001.

[4] Sap2000: Integrated Structural Analysis \& Design Software. Vers. 17. Berkeley, CA. Computer and Structures, 1997.

[5] PEER Ground Motion Database, Pacific Earthquake Engineering Research Center. https://ngawest2.berkeley.edu/. 
[6] Black, G.R., Wenger, B.A. \& Popov. E.P., Inelastic buckling of steel struts under cyclic load reversals. Report no. UCB/EERC-80/40. Earthquake Engineering Research Center: Berkeley, CA, 1980.

[7] FEMA. NEHRP Commentary on the guidelines for the seismic rehabilitation of buildings. FEMA-356, Federal Emergency Management Agency, Washington, DC, 2001.

[8] Karim, K.R. \& Yamazaki, F.A., Simplified method of constructing fragility curves for highway bridges. Earthquake Engineering Structural Dynamics, 32(10), pp. 16031626, 2003. 